\title{
Virtual care with digital technologies for rural and remote Canadians living with cardiovascular disease
}

Ryan Buyting MSc ${ }^{1-6}$, Sarah Melville BSc (Hons.), CRA ${ }^{3-6}$, Hanif Chatur MD, CCFP(EM) ${ }^{5,6}$, Christopher W. White, MD, PhD, FRCSC ${ }^{2,4,5}$, Jean-François Légaré MD, FRCSC ${ }^{2,4-6}$, Sohrab Lutchmedial MD, FRCPC ${ }^{3,4-6} \&$ Keith R. Brunt, $\mathrm{PhD}^{1,5,6 *}$

1. Department of Pharmacology, Dalhousie Medicine New Brunswick, Saint John, New Brunswick, Canada

2. Division of Cardiac Surgery, Saint John Regional Hospital, Saint John, New Brunswick, Canada

3. Division of Cardiology, Saint John Regional Hospital, Saint John, New Brunswick, Canada

4. Horizon Health Network, New Brunswick Canada

5. Faculty of Medicine, Dalhousie University

6. IMPART Investigator Team Canada (https://impart.team/)

Short Title: Virtual care for rural Canadians with CVD

\section{Address for Correspondence:}

Keith R. Brunt, PhD

Dalhousie Medicine New Brunswick (DMNB)

PO Box 5050, 100 Tucker Park Road

Saint John, New Brunswick

Canada, E2L 4L5

Phone: (506) 636-6974

Email: keith.brunt@dal.ca

Twitter: @prof_brunt

Keywords: Telehealth, Telemedicine, Decision Support Systems, Remote Monitoring, Patient Self-Management 
medRxiv preprint doi: https://doi.org/10.1101/2020.12.17.20248333; this version posted December 19, 2020. The copyright holder for this preprint (which was not certified by peer review) is the author/funder, who has granted medRxiv a license to display the preprint in perpetuity. All rights reserved. No reuse allowed without permission.

\section{Summary}

2 Patients living in rural and remote communities' experience diverse challenges to receiving 3 equitable healthcare as is mandated by the Canada Health Act. Advances in virtual care 4 technology may provide practical, economical, and innovative solutions to ensure this for 5 patients in remote and rural living situations. Here we provide a state-of-the-art review of virtual 6 care technologies available to patients with cardiovascular disease living in rural areas of 7 Canada.

\section{$9 \underline{\text { Abstract }}$}

10 Canada is a wealthy nation with a geographically diverse population, seeking health innovations 11 to better serve patients in accordance with the Canada Health Act. In this country, population and 12 geography converge with social determinants, policy, procurement regulations, and technological

13 advances, in order to achieve equity in the management and distribution of healthcare. Rural and 14 remote patients are a vulnerable population; when managing chronic conditions such as 15 cardiovascular disease, there is inequity when it comes to accessing specialist physicians at the 16 recommended frequency_-increasing the likelihood of poor health outcomes. Ensuring equitable 17 care for this population is an unrealized priority of several provincial and federal government 18 mandates. Virtual care technology may provide practical, economical, and innovative solutions

19 to remedy this discrepancy. Here we review the literature pertaining to the use of virtual care 20 technologies to monitor patients with cardiovascular disease living in rural areas of Canada. A 21 search strategy was developed to identify the literature specific to this context across three 22 bibliographic databases. 166 unique citations were ultimately assessed for eligibility, of which 36 23 met the inclusion criteria. In our assessment of these articles, we provide a summary of the 24 interventions studied, their reported effectiveness in reducing adverse events and mortality, the 25 challenges to implementation, and the receptivity of these technologies amongst patients, 26 providers and policy makers. Further, we glean insight into the barriers and opportunities to 27 ensure equitable care for rural patients and conclude that there is an ongoing need for clinical 28 trials assessing virtual care technologies in this context. 
medRxiv preprint doi: https://doi.org/10.1101/2020.12.17.20248333; this version posted December 19, 2020. The copyright holder for this

\section{Introduction}

30 Based on its geographic size and distributed population density, Canada is justified to become a

31 leader of innovation for remote medical care-whether the nation is optimally capitalizing on

32 this is unclear. Rural populations are essential to the well-being of a nation, as they are

33 naturalized environmental stewards; farmers and harvesters providing the majority of food, and

34 other natural resources that enable urban living and a trade economy. In contrast to urban

35 populations, rural patients are a vulnerable group in need of special attention to ensure equitable

36 healthcare delivery. ${ }^{1-3}$ The inequities impacting rural populations are complex, but a major

37 concern is timely access to specialist physicians in accordance with clinical guideline

38 recommendations. ${ }^{4-6}$ Disparities in healthcare negatively impact all clinical outcomes, and thus

39 provisions to secure equitable healthcare and comparable health outcomes for vulnerable groups

40 are necessary. The scientific and clinical efforts toward addressing this are increasing and

41 multiple approaches to democratize care are being studied. ${ }^{7}$ One approach is the opportunity for

42 healthcare workers, researchers, and policymakers to adopt innovative virtual care and remote-

43 monitoring platforms to improve clinical outcomes, reduce hospital wait times, or increase the

44 quality of life for patients and their families. ${ }^{8,9}$ An example of how such a system could work is

45 depicted in Figure 1, which has been adapted from Prescher et al. ${ }^{10}$ In the 1970s, Canada was a

46 leader in virtual care, yet now lags behind other countries. There is increasing demand by

47 Canadian physicians for more virtual care technology, training, and payment models to support

48 and integrate with standard clinical practice. In an organized initiative, the Canadian Medical

49 Association (CMA) Virtual Care Task Force recently created a national strategy of practice

50 recommendations. ${ }^{11}$

52 There is no widely accepted definition of virtual care, telehealth, telemedicine, or e-medicine, 53 and these terms are often used interchangeably, along with many others. The World Health 54 Organization defines e-health as "the cost-effective and secure use of information and 55 communication technologies in support of health and health-related fields, including healthcare 56 services, health surveillance, health literature, and health education, knowledge and research." 12 57 The use of virtual care technologies continues to grow and includes electronic virtual visits, 58 referrals, consults, prescriptions, medical-records, vital sign monitoring, digital therapeutics, 59 care-flow ordered checklists, telepresence and robotic surgery. For the purpose of this review, 60 virtual care is defined as healthcare services provided directly to patients using information 61 telecommunications technology (that is, medical care provided without traditional dependence 62 on physical contact, paper, or archaic technologies such as fax machines). We will refer to all 63 further instances of these terms simply as virtual care. Healthcare providers can use virtual care 
64 to remotely diagnose, treat, and manage patients, in many but not all instances. Thus, virtual care

65 ensures continuity and integration with practice level operations, not displacement or

66 replacement. Patients can be seen virtually by primary care providers in their homes, places of

67 work, or anywhere else they have access to the internet. The ability to connect providers and

68 patients without regard to their respective locations is a compelling benefit of virtual care

69 services for both patients and providers. ${ }^{13}$ It is also considered to be essential infrastructure to

70 occupational health, safety and productivity by employers by reducing down-time, sick-days and

71 an optimized work culture. Virtual care simply provided by video and audio alone has diverse

72 applications, but numerous disease-specific platforms and devices have also been developed to

73 remotely provide the consulting physician with evermore information to improve decision

74 making. These devices include stethoscopes, glucometers, oxygen saturation monitors, weigh

75 scales, temperature, and blood pressure devices, along with more invasive technologies such as

76 otoscopes, continuous positive airway pressure (CPAP) sleep devices, or even implantable

77 cardiac-defibrillators. ${ }^{14,15}$

As was alluded to above, virtual care technologies are not intended to replace traditional healthcare delivery methods, but rather to augment and integrate with services to ensure more productive, efficient, and equitable healthcare for all citizens. Regular health monitoring of patients at-risk of- or diagnosed with- cardiovascular disease (CVD), has the potential to reduce the need for significant treatment interventions, including invasive cardiac surgery or readmissions for past interventions. ${ }^{16-18}$ Virtual care mitigates the need for rurally located patients to defer care or make burdensome commutes to visit with specialist clinicians for follow-up appointments. This can improve post-operative health outcomes. Owing to the fact that these technologies enable more productive, efficient, sustainable, supported, and convenient care management, they have important economic implications to healthcare payers, whether they are government or private allied insurers. CVD ranks among the largest chronic comorbidity and cause of morbidity and mortality in Canada. ${ }^{19}$ Therefore, our research question was directed at understanding: what efforts in the realm of rural CVD management using virtual care technologies have recently been conducted in Canada? The purpose of this review is to summarize the relevant studies, the effectiveness of virtual care systems to reduce adverse

94 events, improve adherence to medication and lifestyle modifications to effect all-cause

95 mortality-recognizing barriers to implementation or acceptance of these technologies among

96 payers, patients, and providers.

97 
medRxiv preprint doi: https://doi.org/10.1101/2020.12.17.20248333; this version posted December 19, 2020. The copyright holder for this preprint (which was not certified by peer review) is the author/funder, who has granted medRxiv a license to display the preprint in perpetuity. All rights reserved. No reuse allowed without permission.

$\underline{\text { Methods }}$

100 Eligibility Criteria

101 Using a priori developed selection criteria, we included studies reporting on the use of virtual

102 care technologies in the context of patients in rural areas of Canada living with CVD. We used

103 the definition of CVD outlined by the World Health Organization's International Classification

104 of Diseases Tenth Edition (ICD-10), which encompasses all diseases of the circulatory system, 105 primarily: 1) coronary artery disease, or ischemic heart disease, caused by low myocardial 106 perfusion, and thus precipitating angina, myocardial infarction, and/or heart failure. 2) 107 cerebrovascular disease, including disorders that affect the blood supply to the brain, including 108 stroke and transient ischemic attack, and 3) peripheral artery disease, involving the limbs or 109 claudication in peripheral vasculature. Additionally, hypertension, valvular pathologies, aortic 110 aneurysms, and cardiac arrhythmias were all considered to be cardiovascular pathologies that fit 111 this definition. ${ }^{20}$

113 This review includes all study designs, including quantitative pilot and retrospective comparison 114 studies, and qualitative analyses of the various aspects involved with the adoption of virtual care 115 technologies by healthcare providers, patients, and their families. Therefore, the population of 116 interest included patients diagnosed with CVD or individuals caring for patients diagnosed with 117 CVD at the time of study. We only included studies that explicitly mentioned rurally located 118 patients living in Canada, as the economic and political climate of a particular healthcare 119 network has proven to be a critical factor regulating how these virtual care technologies are 120 being disseminated and studied. Despite this, in some subsections, we reflect on Canadian 121 studies that do not explicitly focus on rural patients in order to contextualize the state of the 122 technology for a given disease. The articles also had to have been published in English within the 123 last 10 years, due to the fact that the technology is rapidly evolving, and older technologies are 124 becoming irrelevant.

\section{Literature Search Strategy}

127 Literature search strategies were developed with the assistance of an experienced information 128 services librarian (JP) who reviewed and refined the search criteria through iterative discussion.

129 We adopted relevant elements of the Preferred Reporting Items for Systematic Reviews and 130 Meta-Analyses (PRISMA). ${ }^{21}$ A search of the literature was performed by the primary author 131 (RB) in May of 2020 using PubMed (C), Embase $®$, and the Cochrane Central Register of 132 Controlled Trials (CENTRAL) (C). All articles that listed in the title or abstract the terms 133 "telehealth," “omnicare," “e-medicine," “electronic medicine," "remote consultation," or

134 "telemedicine" were linked through the Boolean operator "and" to rural-patient-identifying terms 
135 ("rural," "remote," "distance," "rural population," and "rural health services"), as well as the

136 terms "Canada," and terms relating to the diseases of interest ("hypertension" or "cardiovascular

137 disease"). MeSH terms were used where appropriate and when possible. Using the features built

138 into each of these respective databases, the results were limited to studies published in English

139 within the last 10 years before being imported into Covidence C.

140

141 Study Selection

142 Upon being imported into the review software, any duplicate articles were automatically

143 removed. The remaining titles and abstracts were screened for relevance to the research question

144 by the primary author (RB). Articles were removed if they did not meet the a priori defined

145 criteria. The full texts of each of the remaining articles were then individually obtained and

146 reviewed in-depth to determine their applicability. At this stage, each article was either removed,

147 or included and subsequently categorized based on the subtype of CVD in the study. A

148 miscellaneous category was created for studies that included multiple CVD subtypes. A total of

149166 citations were identified and assessed for eligibility, yet only 36 studies met the inclusion

150 criteria and are discussed in this review. (Figure 2) 
medRxiv preprint doi: https://doi.org/10.1101/2020.12.17.20248333; this version posted December 19, 2020. The copyright holder for this preprint (which was not certified by peer review) is the author/funder, who has granted medRxiv a license to display the preprint in perpetuity. All rights reserved. No reuse allowed without permission.

\section{$\underline{\text { Results }}$}

\section{Study Characteristics}

153 The studies that met the inclusion criteria of this review discussed virtual care programs from 154 five provinces: Ontario (15), British Columbia (10), Alberta (8), Quebec (2), and Saskatchewan 155 (1). One study specifically included Indigenous Nations in three provinces (ON, QC, \& NB), 156 which strengthens the validity of inclusiveness in a rural Canadian context for that study. The 157 Western Prairies (AB, SK, MB), Atlantic Canada (NB, NS, PE, NL), and Territories (YT, NT, $158 \mathrm{NU})$ are discussed collectively due in part to collective geographic rural regionality. The article 159 types include: 2 review articles, 1 commentary article, 1 protocol paper, and 32 original research 160 articles (15 abstracts and 17 full-length manuscripts). The articles were published from 2010 to 161 2019, with more than a third $(n=13)$ published in $2018(n=6)$ and $2019(n=7)$. The total number 162 of participants in all of the studies combined was $4,014$.

\section{General Cardiovascular Disease Interventions}

165 Jarvis-Selinger et al. interviewed 48 stakeholders who were either patients diagnosed with CVD 166 or involved in the care of patients diagnosed with CVD from rural and urban areas of British 167 Columbia. Their goal was to better understand the role of virtual care in CVD management, the 168 challenges to its adoption, and incentives that may increase its use among this population. The 169 findings suggest that both healthcare providers and patients supported the use of virtual care, 170 with the greatest benefits derived from the ability to share patient data and support patient selfmanagement. Two concerns commonly expressed were the accuracy of patient self-reported data

172 and security, therefore the authors state that support for implementing such systems needs to be 173 tempered by a clear understanding of how these concerns will be mitigated. ${ }^{22}$ Some reassurance 174 may be derived from the fact that many of these systems include automatic vital sign reporting to 175 the provider (as well as an option for manual input by the patient), and most devices adhere to 176 federal regulatory standards with respect to privacy and security. Further support for the role of 177 virtual care among rural patients comes from Cameron et al., who trialed a chronic disease self178 management program in 13 rural and remote communities in Northern Ontario over a 9-month 179 period. A total of 213 individuals with diagnoses of chronic lung disease, CVD, stroke, or 180 arthritis were included in the study. While their goal was to better understand the psychological 181 mechanisms underlying the effectiveness of the program itself (rather than its delivery), the fact 182 that it was successfully conducted in this manner alone is encouraging. Specifically, the results 183 of this study show that virtual care initiatives can be a viable means of overcoming geographic 184 barriers for rural patients, and that patients and providers in rural areas may be uniquely 185 receptive to these innovations. Outcomes produced from these programs, including those related 186 to self-efficacy, mental- and physical-health status, can be comparable to in-person programs, 
187 thereby enhancing the overall reach and equity of healthcare services. ${ }^{23}$ Other evidence shows

188 that virtual care technologies used with regular exercise can improve patient cardiometabolic risk 189 profiles; Stuckey and colleagues investigated the effects of an exercise prescription alone 190 compared with a program supported by virtual care technology to improve cardiometabolic risk 191 factors in rural community-dwelling adults. This work, however, seems to be ongoing, as only 192 the rationale for this project could be sourced. ${ }^{24}$ It is generally considered to be more effective to

193 actively engage and support the person or population in establishing lifestyle changes, and with 194 the aid of virtual care, this coaching could be delivered faster and at scale. However, more robust 195 evidence from such programs (be it public or private) are needed to drive policy or practice 196 changes.

\section{Heart Failure Interventions}

199 Andrikopoulou and colleagues described a conceptual model of heart failure (HF) disease 200 management, in which they state that virtual care is effective because it allows for early detection 201 of worsening HF symptoms. Further, device data may prompt providers to optimize medication 202 regimens and may allow patients to better understand their unique causes of decompensation. ${ }^{25}$ 203 In their 2012 article, Grant et al. describe the first Canadian experience using virtual care for a 204 small sample of 25 HF patients, in which they found similar benefits, resulting in a reduced rate 205 of all-cause patient admissions and no admissions for HF decompensation. They stressed that the 206 success of this program was attributable to the cardiovascular nurses' ability to assess and 207 manage these complex patients and are therefore a key factor in the effectiveness of this model 208 of care. ${ }^{26,27}$ Toback et al. later agreed with this sentiment, stating that effective virtual nursing 209 can improve patient education and self-management, including management of worsening 210 symptoms, daily weight measurements, medications and adjustments, appointment attendance, 211 diet restrictions, and appropriate behaviours based on symptoms and weight changes. ${ }^{28}$

213 Telehealth for Emergency-Community Continuity of Care Connectivity via Home

214 Telemonitoring (TEC4Home) is a 4-year long initiative throughout many urban and rural centres 215 in British Columbia that aims to determine how virtual care may improve care, increase patient 216 safety during the transition of care, and determine how it is best implemented to support patients 217 with HF. ${ }^{29}$ Though still ongoing, results from their intermediary pilot study indicate that home 218 monitoring of HF patients decreased emergency department visits and improved the overall 219 patient experience. The length of stay data presented in the abstract suggests that patients could 220 be discharged from the emergency department with home monitoring in order to reduce 221 hospitalization. ${ }^{30}$ Given these preliminary results, we look forward to the pending release of a 222 peer-reviewed publication containing the results of this study. 
medRxiv preprint doi: https://doi.org/10.1101/2020.12.17.20248333; this version posted December 19, 2020. The copyright holder for this preprint (which was not certified by peer review) is the author/funder, who has granted medRxiv a license to display the preprint in perpetuity. All rights reserved. No reuse allowed without permission.

Jaana and Sherrand assessed the comparative utilization of virtual care among patients with HF in rural versus urban environments. They describe the necessity of considering the context in which these interventions take place, which varies based on the geographic location of the patients, as manifested by a variation in the social environment, individual resources and capabilities, and the need for technology; this last point was specifically defined as a situation where virtual care can substitute for services that have disappeared or supplement existing services in a way that rural residents perceive as useful. ${ }^{31,32}$ This group conducted a crosssectional study of all patients enrolled in the virtual care program at the University of Ottawa Heart Institute. They assessed variables associated with both the processes and outcomes of care, including the frequency in which: a patient's vital signs were out of normal range, calls were made to a patient by the nurse, emergency department visits, hospital admissions, etc. Interestingly, there was no variation in the process or outcome measures, thus concluding that rural patients may not be perceived as extensive users of resources, nor patients who represent challenges in terms of feasibility of virtual care use. ${ }^{31}$ This is encouraging, as it suggests that rural patients, who have the potential to benefit more from virtual care services than their urban counterparts, should not feel that they are being perceived as 'stealing healthcare dollars' from urban taxpayers when advocating for its increased promotion and use within rural communities.

\section{Cardiac Arrhythmia Interventions}

Current practice guidelines for the treatment of cardiac arrhythmias in Canada recommend that patients with cardiovascular implantable electronic devices (CIED), undergo follow-up assessments at regular intervals. ${ }^{33-35}$ Herein lies an opportunity for innovation and optimization through the implementation of virtual care technology. Amelio and colleagues describe one of the initial Canadian virtual care arrhythmia clinic experiences, which aims to improve access to electrophysiologists in Alberta. Patients are seen through a half-day clinic, scheduled on a monthly basis, by both a registered nurse and an electrophysiologist. Through a video-conference interview combined with diagnostic data supplied from the distant site, they develop a diagnosis and provide treatment options, with on-going follow-up by a nurse to ensure patients are properly managed. Patients reported satisfaction with this system and indicated saving up to $\$ 500 \mathrm{CAD}$ in expenses and over 500 kilometres in travel for each appointment. ${ }^{36}$

In 2013, the Canadian Cardiovascular Society and Canadian Heart Rhythm Society released a position statement regarding the use of virtual care technology for CIED follow-up. It reported that integrating these technologies into clinical practice can accelerate the identification of clinical events and device problems, therefore recommending that virtual care be available at all CIED follow-up clinics as standard of care. The report also provides advice for the proper 
medRxiv preprint doi: https://doi.org/10.1101/2020.12.17.20248333; this version posted December 19, 2020. The copyright holder for this preprint (which was not certified by peer review) is the author/funder, who has granted medRxiv a license to display the preprint in perpetuity. All rights reserved. No reuse allowed without permission.

design, implementation, and integration of a virtual care system, albeit not unique to rural populations. ${ }^{35}$

Saint Paul's Hospital in Vancouver reported that using virtual care in their CIED care processes decreased patient anxiety levels, improved communication of device information, and allows patients living in rural communities' access to specialized care. Furthermore, they state that this integration has also presented challenges, such as changes to clinic workflow, compliance and usability by patients, and the need to develop effective education strategies when initiating monitoring with new patients. ${ }^{37,38}$ Similarly, Sparkes et al. conducted a usability study of a mailable, non-invasive cardiac testing kit to five participants, each with varying experience with technology. This specific application required independent set-up by patients, who were recorded doing so in a 'think aloud' manner, while completing 20 device set-up tasks, followed by an interview to elucidate their feelings about the process. While gender, age, and familiarity with technology seemed to influence the participants' abilities to successfully set up these devices, they concluded that sending the kit by mail appeared to be an acceptable strategy. ${ }^{39}$ However, given the small sample size, larger studies that could help to confirm these results are warranted. These could help to further elucidate the language that should be used in the instructions and the obstacles that should be anticipated in future deployments. Taken together, these studies show the importance of involving patients as stakeholders when designing virtual care technology and dissemination strategies. Also, if designed correctly, patients may not need to attend a preliminary face-to-face visit with their care providers before initiating a virtual care-based healthcare relationship. Established self-learning and orientation by video or walk-through modules is one way to empower patients in this regard.

Rush et al. from the University of British Columbia has done extensive research into the perspectives of physicians and patients living in rural areas concerning the use of virtual care for atrial fibrillation (AF), specifically. In a preliminary study, thematic analysis of semi-structured interviews with 14 patient and physician stakeholders revealed a high degree of variability in receptiveness to virtual care. This was reported to be a result of differences in past experiences with virtual care, in perceived adequacy of rural health services, and in perceived gaps in AF care. ${ }^{40}$ In a follow-up study with over 10 -fold more patients $(n=116)$ from three rural communities, there were similar problems in managing AF. As it relates to virtual care, these researchers found that access to primary and cardiology care was a recurring challenge, and

292 emergency department use was highly contentious but often the only option for accessing care.

293 Primary care physicians were generally comfortable managing AF but varied in their reasoning

294 for making referrals to specialists, often reserving them for complex situations to avoid the need 
medRxiv preprint doi: https://doi.org/10.1101/2020.12.17.20248333; this version posted December 19, 2020. The copyright holder for this preprint (which was not certified by peer review) is the author/funder, who has granted medRxiv a license to display the preprint in perpetuity. All rights reserved. No reuse allowed without permission.

295 for patient travel. The patients and providers supported a broad approach to virtual care of AF 296 that is tailored to be inclusive of patients living in a rural demographic and thereby preserve the 297 vital role of primary care physicians. ${ }^{41}$

Ischemic Heart Disease Interventions

300 Accurate and efficient interpretation of pre-hospital 12-lead electrocardiograms (ECGs) has 301 shown to produce favourable patient outcomes as it reduces the delay to reperfusion through 302 fibrinolysis or percutaneous coronary intervention (PCI) therapies. ${ }^{42}$ Tanguay and colleagues 303 reported on a virtual care-based STEMI detection program used throughout rural Quebec. This 7304 year retrospective study included 728 patients with suspected STEMI who were transported by 305 EMS. The transmission of an ECG every two minutes allowed for remote interpretation of 306 abnormalities by a physician to discern between patients with a STEMI and those with a non307 STEMI. The system enabled remote diagnosis of STEMI in $8.1 \%$ of patients during transport 308 following an initial non-STEMI diagnosis. Thus, serial monitoring of these dynamic changes can 309 allow for more rapid diversion to primary PCI facilities, potentially improving outcomes. ${ }^{42}$ Such 310 an approach could also lend itself well to machine learning decision support systems that 311 improve triage or follow-up.

313 The American Heart Association guidelines recommend that the time between first medical 314 contact and balloon inflation for STEMI patients should not exceed 90 minutes. ${ }^{43}$ However, this 315 is not realistic for many rural health systems, leading to increased morbidity and mortality for 316 patients in these areas. The same group in Quebec also strove to address this issue by using 317 virtual care services to reduce pre-hospital delays and make timely STEMI diagnoses. Over a 318 similar 7-year time period, their retrospective data of 208 STEMI patients demonstrated that $31914.9 \%$ were already on their way to a hospital with PCI capabilities, $75.0 \%$ were re-routed to a 320 PCI centre, and $10.1 \%$ were directed to the nearest hospital. All patients but one arrived at the 321 PCI centre within the guideline recommended 60-minute pre-hospital care interval. This study 322 further illustrates that virtual care can help give timely access to PCI for rural populations that 323 would not otherwise have access to this treatment. ${ }^{44}$ Integrating virtual care with paramedic and 324 emergency departments can further augment this capacity to deliver on-time care to rural 325 patients. Despite this however, one could argue that truly remote patients will never be able to 326 reach a PCI centre within the recommended time window, and thus these results may not be 327 applicable.

329 Following an acute event of cardiac ischemia, cardiac rehabilitation programs, consisting of a 330 combination of lifestyle and risk-factor management, can improve psychosocial outcomes and 
medRxiv preprint doi: https://doi.org/10.1101/2020.12.17.20248333; this version posted December 19, 2020. The copyright holder for this preprint (which was not certified by peer review) is the author/funder, who has granted medRxiv a license to display the preprint in perpetuity. All rights reserved. No reuse allowed without permission.

331 reduce both premature mortality and future cardiac events. Given that these programs are 332 traditionally offered in large urban centres, geography is a common reason for decreased 333 attendance and inaccessibility. The review by Lear summarizes key work done in Canada that 334 leverages virtual care technologies for use in remote cardiac rehabilitation programs. ${ }^{45}$ Lear et $335 a l$. also conducted a pilot study followed by a scaled, randomized controlled trial; the trial was a 336 4-month virtual care-based program with a 1-year sustainability follow-up on exercise capacity 337 and risk factor reduction compared with usual care. Only patients living in rural areas of British 338 Columbia were enrolled, as this population was thought to benefit most from a virtual care 339 program. For the primary outcome, after adjustment for the maximal time on the treadmill at 340 baseline, age, sex, type 2 diabetes, and internet use for health information, participants in the 341 treatment group had a greater increase in maximal time on the treadmill by 45.7 (95\% CI, 1.04$34290.48)$ seconds compared with the control group during the 16 months $(P=0.045)$. In unadjusted 343 analyses, total cholesterol $(-7.3 \%$; $P=0.026)$, low-density lipoprotein cholesterol $(-11.9 \%$; $344 P=0.022)$, and dietary saturated fat $(-1.4 \% \mathrm{kcal} / \mathrm{d} ; P=0.018)$ were lower for the treatment group 345 and required minimal resources with less than 8 hours of staff time per patient. Therefore, this 346 model of care is cost efficient and readily sustainable. ${ }^{46}$ A qualitative analysis of patient347 physician discussions when using this virtual program has also been published, which suggests 348 that simple chat sessions can be an effective alternative to in-person consultations, when necessary. ${ }^{47}$

Pistawka et al. also conducted a virtual cardiac rehabilitation program in British Columbia that delivered health education to seven rural communities with a high prevalence of ischemic heart disease. The program was implemented over a 6-month period in partnership with local health authorities to ensure optimal uptake, ease of accessibility, and a streamlined referral process. This was followed by a six-week evaluation period, revealing robust patient interest, uptake, 356 personal satisfaction, and improved self-efficacy, with over $90 \%$ of the study participants feeling 357 more knowledgeable with better skills to manage their health. ${ }^{48}$ This further emphasizes the importance of working with policy experts and procedural gatekeepers in health authorities to streamline innovation implementation and pilot processes.

\section{Hypertension Interventions}

362 The prevalence of hypertension in Canada continues to rise and coordinated efforts to improve 363 the treatment and control of hypertension are needed. ${ }^{49}$ Despite the high prevalence, there is 364 currently only one primary research article that investigated the use of virtual care for patients 365 living in rural areas. Tobe et al. conducted the Diabetes Risk Evaluation and Management 366 (DREAM)-global study to improve hypertension awareness, treatment, and management in 
medRxiv preprint doi: https://doi.org/10.1101/2020.12.17.20248333; this version posted December 19, 2020. The copyright holder for this preprint (which was not certified by peer review) is the author/funder, who has granted medRxiv a license to display the preprint in perpetuity. All rights reserved. No reuse allowed without permission.

367 Indigenous populations living in rural areas using virtual care. ${ }^{50-52}$ They randomized 243 368 patients from six rural communities to receive text messages specific to hypertension 369 management (active group) or general good health behaviours (passive group) and assessed for 370 reductions in blood pressure over a one-year period. Despite an overall reduction in blood 371 pressure, there was no difference in the blood pressure change between groups from baseline 372 systolic $0.8(95 \% \mathrm{CI}-4.2$ to $5.8 \mathrm{~mm} \mathrm{Hg})$ or diastolic $-1.0(95 \% \mathrm{CI}-3.7$ to $1.8 \mathrm{~mm} \mathrm{Hg}, \mathrm{P}=0.5)$ 373 blood pressure. Control was achieved in 37.5\% (25.6\%-49.4\%, 95\% CI) of the active group and $37432.8 \%(20.6 \%-44.8 \%, 95 \% \mathrm{CI})$ of the passive group (difference in proportions $-4.74 \%(-21.7 \%$ 375 to $12.2 \%, 95 \% \mathrm{CI}, \mathrm{P}=0.6)$. This suggests that virtual care can be effective for controlling blood 376 pressure for Indigenous community members under the direction of community leadership. ${ }^{52}$ In 377 an editorial commentary about this study, Padwal suggests that passive virtual care interventions 378 like text messages are unlikely to be effective and that more dynamic interventions such as teletransmitting blood pressure devices are a better strategy. ${ }^{53}$ Further cultural engagement with

380 Indigenous communities is needed to have two-eyed seeing initiated with Indigenous ways of knowing to approaches and goals for CVD management. ${ }^{54}$

\section{Cerebrovascular Disease Interventions}

384 The phrase "time-is-tissue" is used by cardiologists and neurologists to emphasize that tissue is lost quickly as an infarction progresses without reperfusion; so emergent evaluation and rapid responsive therapy are required. ${ }^{55}$ For this reason, virtual care is paramount to individuals affected by- and involved in the care of- patients with these conditions when geographically distant from healthcare centres specializing in stroke treatment. The Canadian Stroke Best Practice Guidelines state that virtual care services are a cost-effective tool to support health systems in closing the urban/rural and tertiary/primary care gap. ${ }^{56}$ virtual care is safe and achieves similar clinical outcomes as the same treatment delivered at stroke centres. He further suggests that a virtual care approach could be used to provide training, teaching, and therapy in the recovery phase for stroke patients living in remote regions. ${ }^{57}$ Zimmer et al. discuss the training necessary to establish a stroke-focused virtual care system 397 using a clinical toolkit in the Ontario Stroke System. The key components include clinical 398 workflow algorithms, nursing/physician competencies, an education/training flowchart, 399 protocols, technical readiness, evaluation tools, and resource contact information. Results from 400 their study suggest that this training system facilitated efficiencies and standardization of practice 401 to ensure optimal acute stroke management. ${ }^{58}$ Taralson and colleagues also studied a similar 402 training protocol applied in Alberta. They identified that an enthusiastic local leadership team, 
with strong physician support, and an equally supportive hub site stroke team are necessary for the implementation of successful remote stroke centres. Regular participation in mock code drills could also improve staff confidence and competency, leading to better patient outcomes. ${ }^{59}$ This program established and developed evidence-based guidelines in order to implement virtual care across the continuum of stroke care. ${ }^{60}$ Glasser and colleagues comment on the specific nursing competencies required to effectively use virtual care technology in this context, and stated that interpersonal communication and collaboration, and technology-related skills including the security of data and effective documentation of virtual visits are key areas to focus. ${ }^{61}$ In patient

411 centered care, where a degree of cognitive impairment is certain, facilitated care management

412 using virtual care, appointment and instructional supports serves the individual and their 413 informal care providers.

Khan et al. recounted one of the first Canadian virtual care experiences for acute stroke treatment in remote regions in which a critical care line was used by distant sites to connect to a physician with stroke-expertise at a hub site for patient examination and computed tomography (CT) scan assessment via a two-way video and audio link. Over a two-year period, the system was used 211 times, of which 45 patients $(21 \%)$ were treated effectively without transfer. In this study, the number of transfers decreased $92.5 \%$ from 144 to 15 at one of the remote sites. These results suggest that virtual care could lead to a reduction in the number of patients requiring transfer to a tertiary care center benefiting quality of life and health economics. ${ }^{62}$ Silver later provided an editorial commentary regarding the results-stating that the number of patients in the specific subgroups are too small to draw firm conclusions, but that the results suggest that virtual care could be non-inferior to in-person care in these settings. ${ }^{63}$ Stroke quality indicators were later compared between patients treated remotely using this program and those who received care from an on-site stroke specialist, showing that they were indeed comparable. ${ }^{64}$ Similar results were reported for the Ontario system. ${ }^{65}$ The rationale for not yet nationalizing such a virtual care program remains unclear.

There is a need for CT-scans to assess cerebrovascular accidents to rule out brain haemorrhage risk prior to thrombolysis. This expensive equipment is not widely available in rural areas and remote healthcare sites, yet portable CT-scanners are brought into these rural sites and can be

434 operated after minimal training. A portable CT-scanner at a remote site was implemented in the 435 evaluation of patients who were not within timely reach of stroke experts. ${ }^{66}$ Recently, a CT436 equipped stroke ambulance was used to enable brain imaging at the patient's location. This 437 example of advanced paramedic technology suggests the potential for decentralizing care in 438 remote areas to bring the "hospital to the patient." While initial success has been documented, 
the question of cost-effectiveness, particularly in the rural setting, requires further study and is an important part of ongoing research studies. ${ }^{67}$ Lastly, Mitchell et al. did a study about a promising radiology-focused emergency medicine program that would allow for urgent detection of brain hemorrhages, which could play an important role in the future of virtual care-based stroke care. ${ }^{68}$

The disparities in CVD rates among Canadian Indigenous populations contribute to increased rates of stroke, and therefore some researchers have partnered with Indigenous organizations to work towards developing culturally appropriate services and support programs. Bodnar reported on projects undertaken within the Northwestern Ontario Regional Stroke Network centered around the development of educational materials and strategies, and virtual care-based initiatives designed to meet the unique needs of Indigenous peoples. ${ }^{69}$ After stroke, extensive rehabilitation is often needed, involving physiotherapists, occupational (OT) and speech therapists, and social workers, many of whom are not accessible to remote populations, nor trained in cultural safety aligned with community values. French and colleagues reported on a multidisciplinary virtual care solution; over a five-month period, 10 consultations took place, with an average of 7.22 recommendations and referrals per visit (range 4-10). These consultations focused on mobility, education, resuming roles, and community participation. The experience was rated good to excellent by both patients and clinicians for $95.2 \%$ ( $\mathrm{SD}=0.44)$ of the consultations. However, audio quality was rated as poor to fair by the patients in $75.0 \%$ ( $\mathrm{SD}=0.82)$ of visits. All participants reported as willing to recommend the system to others. As is a common theme in this review, healthcare, community, and virtual care partnerships were critical to the success of this program. ${ }^{70}$ Linkewich and colleagues reported on an analogous virtual care tool used to conduct OT home safety assessments for a similar patient population. The OTs who participated reported confidence in making practice recommendations using the program, however, a comment about needing to "sense" the client in a different way was repeatedly made, suggesting that reduced non-verbal body language could be a disadvantage of the tool. The client and all OTs were willing to recommend the virtual assessment system. Audio quality was also reported to be problematic, as in the previous study. ${ }^{71}$ Technology based experiential quality is a

468 surmountable issue and can be overcome through cell-tower and emerging satellite high-speed 469 connectivity. These findings also emphasize the goal of virtual care should not be to eliminate in470 person systems but rather focus them and integrate with it for productivity, efficiency, and 471 patient outcome or experience benefit.

473 Moving On after Stroke (MOST®) is a group-based, self-management program for stroke 474 survivors and their caregivers consisting of information sharing, facilitated discussions, goal- 
setting, and physical exercise. Taylor et al. simultaneously delivered the program to local participants onsite in Thunder Bay, Ontario and via virtual care to participants living in small, remote communities. Their objective was to explore the experiences of remote participants and their perceptions regarding factors that enable or limit their participation, and to obtain suggestions for enhancing delivery. As such, we can appreciate the preventative health benefit of virtual care. Interviews, followed by thematic analysis, with 19 participants revealed that there was value in not having to travel long distances for appointments. Many patients reported "feeling as if they were in the same room" but some patients acknowledged that there were limitations such as a loss of subtleties in communication. Some facilitators found it difficult to discern whether the exercise routines were appropriate for the participants. A preliminary faceto-face meeting and enhanced local support were found to improve the experience. ${ }^{72}$ Patient compliance and preventative health can be a combined consideration in healthcare and environmental sustainability-respect the person and the planet by reducing the distance between people.

Whelan et al. reported results from the Saskatchewan Cerebrovascular Center virtual care study regarding consults and post-operative follow up visits. Over a two-year period, 184 patients who were surveyed following virtual visits saved an average of 243 kilometres, which was a cumulative total of 43, 948 kilometres saved and an average patient-perceived financial savings of $\$ 445$ CAD per visit. All but one patient (94\%) reported being satisfied. However, all patients were willing to use the system again. ${ }^{73}$ Sakakibara et al. reported findings of a similar program based in Vancouver, whereby 102 patients (of which 37.2\% were rural) completed a survey about their experiences using a system designed specifically for low-cost consumer technologies. While they found that the delivery of rehabilitation services using these technologies was both feasible and desirable by many stroke survivors, $71 \%$ of respondents believed their quality of care would be less than in-person rehabilitation. Therefore, the authors concluded that virtual care should augment and not replace in-person rehabilitation, but in cases where in-person rehabilitation is neither accessible nor possible, then virtual care is an acceptable substitution. ${ }^{74}$

503 Lastly, Appireddy, et al. reported results from a 6-month study using virtual care for post-stroke 504 follow-up care throughout the Kingston Health Sciences Centre in Ontario. This study included

50575 participants (of which 39\% were rural) and they found that: 1) There was a statistically 506 significant shorter wait-time for a virtual appointment compared to in-person (median 60 vs 78 507 days). 2) The virtual care visits were also shorter in duration, taking on an average of 10 minutes 508 to deliver follow-up care with a high degree of patient satisfaction versus an average of 90 509 minutes for in-person care. 3) On average, the total time saved by patients per visit was 80 510 minutes, of which 44 minutes was travel time. 4) Travel distance avoided by the patients was an 
511 average of $30.1 \mathrm{~km}$. 5) The estimated total out-of-pocket cost savings for patients per visit was 512 \$52.83. 6) The estimated savings (opportunity cost for in-person outpatient care) for their entire 513 virtual care pilot project was $\$ 23,832$ - \$28,584 CAD. The patient satisfaction with the virtual 514 system was good compared with their prior personal experience with in-person outpatient care. ${ }^{75}$

515 A point worthy of exploration is the discrepancy in patient cost-savings mentioned in this study 516 as compared with the figures cited previously of $\$ 445$ and $\$ 500 \mathrm{CAD}$. The fact that this study 517 contained only $39 \%$ rural patients, whereas the other two studies were entirely composed of rural 518 patients may indicate that much of the cost-savings are likely related to food, parking, 519 accommodation, and not simply mileage. This discrepancy may also reflect the fact that rural 520 Saskatchewan and Alberta have greater cost to distance travel ratios than Ontario, or perhaps the 521 cost discrepancy is due to lack of inflation adjustment. Incorporating health economic analyses to 522 virtual care pilots, implementation, monitoring should be emphasized. Health value 523 demonstration initiatives are ideally well powered and longitudinal partnerships between 524 academic institutes and health authorities. 
medRxiv preprint doi: https://doi.org/10.1101/2020.12.17.20248333; this version posted December 19, 2020. The copyright holder for this preprint (which was not certified by peer review) is the author/funder, who has granted medRxiv a license to display the preprint in perpetuity. All rights reserved. No reuse allowed without permission.

\section{$\underline{\text { Discussion }}$}

526 To our knowledge, this is the first review of recent publications that examines the use of virtual 527 care technology seeking to benefit patients with CVD who are living in rural Canadian locations.

528 We have attempted to understand the effectiveness of the various interventions, which have 529 generally had positive effects among the patient population of interest. The specific subjective 530 benefits of virtual care include reduced hospitalization and readmissions, improved mortality 531 rates, increased cost-effectiveness for patients and hospitals, improved quality of life for patients, 532 and an increase in self-management of CVD. Further benefit is derived through better disease 533 prevention and increased patient investment in their health span. Virtual care is not a panacea for 534 all rural medicine needs. However, it is clear that value is being extracted, predominantly by 535 three Canadian provinces (BC, ON, and QC), which is surprising since these provinces have the 536 greatest urban concentrations of people. ${ }^{76}$ These provinces also account for the majority of 537 research pertaining to rural medicine in general, which indicates potential inequities in medical 538 research contrary to the objectives of the Canada Health Act. Remarkably, the Western Prairies, 539 Territories, and the Atlantic provinces (with seemingly the most need and the most to gain from 540 virtual care innovations) are not well represented in this subsection of the literature. In the 541 Canadian context, this puts all provinces at a disadvantage by being over-reliant on health 542 transfers from the federal government instead of leadership by strength. Establishing an online, 543 virtual care institute amongst low population density provinces might be possible, yet most 544 supercluster and centers of excellence are concentrated in dense urban zones. Exploring this 545 potential inequity from a legal, social and humanities perspective should be of interest to 546 researchers moving forward.

548 While still largely unadopted on a national level, the data indicates that systems in place for 549 acute pathologies like stroke and STEMI are the most well-established and far-reaching, while 550 systems focused on more chronic subtypes of CVD like HF, hypertension, and arrhythmias, are 551 lagging and largely remain in the pilot phase. This is an important point to highlight, as the 552 management of chronic disease is likely to have the greatest impact. Studies performed within 553 government by health departments or industry in the form of white papers, were inaccessible for 554 review. As a result, very few randomized control trials were identified and much of the work in 555 this area is only being shared in conference proceedings. In the wake of the COVID-19 556 pandemic, this dynamic is likely to rapidly evolve given the expedited policy changes 557 surrounding the use of virtual care technologies. ${ }^{77}$ Innovative solutions like the ones discussed 558 here are now of critical importance given their ability to reduce contact between healthcare 559 providers and vulnerable patient populations. 
medRxiv preprint doi: https://doi.org/10.1101/2020.12.17.20248333; this version posted December 19, 2020. The copyright holder for this preprint (which was not certified by peer review) is the author/funder, who has granted medRxiv a license to display the preprint in perpetuity. All rights reserved. No reuse allowed without permission.

560 Overall, there is an interest to support virtual care among the stakeholders investigated in this 561 study, despite some perceived barriers when compared to in-person approaches to healthcare. 562 Despite this enthusiasm, there is still insufficient evidence to objectively support the outcomes, 563 health economics, physician/patient-satisfaction, and privacy concerns due to a lack of trials and 564 peer-reviewed evidence at this time. CVD risk factor management using virtual care needs peer reviewed study in the Canadian context to build an evidence base that informs policy development. Such studies should emphasize the rationale, define the intended benefit and the comparator arm, and address cost-effectiveness or any barriers to implementation. Until that time, it remains presumed but uncertain that virtual care in Canada can assist in the prevention of CVD, when compared with more specified conditions requiring interventional support.

Despite the fact that the collective studies lacked the desired scientific rigour, or are of limited meta-data, the qualitative insights provide valuable recommendations for researchers planning to deploy virtual care technologies in the future. These have been summarized in Figures 3 and 4. Briefly, a common point of note was the need to involve patients as stakeholders during the planning of virtual care distribution strategies. Kim and colleagues provide insightful commentary as to how best to involve patients. ${ }^{78}$ Another was the need to clarify the roles and responsibilities of all members of the healthcare team related to the virtual care system, specifically stressing who will be responsible for the training of patients and informal care providers. This may represent an obstacle best overcome by online education videos or other patient assistive products and services. Role clarification is needed between the payer and the provider for services and should be explored in future studies. Canada remains predominantly a single/public-paying system and is slow to integrate innovations predominantly developed by the private sector. Establishing a priori criteria to be met by the private sector to deliver virtual care would be welcomed, as the preferences of payers are a critical policy consideration for health authorities. Establishing victory conditions (that is, clear target endpoints), would avoid any further languishing of incorporating healthcare technology innovation that is greatly needed, and so as to be prepared for crisis rather than react to it in the example of implementing virtual care during a pandemic.

The current disparities in health metrics suggest that patients in rural areas, particularly Indigenous nations, desire greater diversity in healthcare delivery, desire to contribute culturally and require specific accommodations. In addition to virtual care services, advanced care 593 paramedics, mobile care units, increased scope of practice for rural pharmacists, augmented extramural nursing and home care options, and physician assistants, could all contribute to rural healthcare teams. Many of these auxiliary topics, in addition to the challenges of policy and 
596 privacy, were not well addressed in these studies and should be the subjects of future research

597 and policy development. Similarly, little in the way of economic analyses were reported, nor is 598 there a consensus for adopting cost-saving or cost-deferring innovations or establishment of 599 time-dependent value-thresholds. Those studies that did report on the cost savings of the 600 intervention averaged $\sim \$ 475 \mathrm{CAD}$ per appointment for patients living in rural communities. 601 Using a reported rural Canadian population of 19\%, data showing 500,000 HF patients, and an 602 estimated $10 \mathrm{HF}-$ related healthcare appointments per year per patient, equating to \$451Million 603 CAD in lost opportunity, illustrating that virtual care tools could significantly reduce out-of604 pocket expenses for patients. ${ }^{79,80}$ To further illustrate, we will assume that $60 \%$ of all in-person 605 visits could be performed using virtual care tools and systems, as has been the low estimate 606 during the COVID-19 pandemic. The Commonwealth Fund reports that the average annual 607 physician visits per capita in Canada in 2017 was $6.8 .{ }^{81}$ For a current population of 37.59M, and 608 an opportunity cost ranging between $\$ 31-\$ 500 \mathrm{CAD}$ per visit, this extrapolates to potential cost 609 savings of $\sim \$ 4.8-\$ 77$ billion CAD. This is to say nothing with respect to the cost savings for the 610 healthcare system itself, which would likely be enough to recoup the costs of purchasing and 611 implementing a virtual care system within a short period of time. Industry partnered health value 612 demonstration initiatives dedicated to regions with a high need can accelerate access to this

613 opportunity by engaging with academic institutes and health authorities in tri-lateral objectives to 614 patient-centered care.

\section{Study Limitations and Strengths}

617 This systematic review has limitations. We evaluated published articles written in English from 618 three relevant databases, therefore, virtual care interventions described in other languages or 619 those not peer reviewed but communicated internally within government health departments 620 were likely missed. Additional search results might have been found in other databases and 621 sources (eg, grey literature, books) and were therefore not included in this review. We also did 622 not evaluate articles that were published prior to 2010 , as we decided that 10 years was a 623 sufficient amount of time to gather material germane to our objectives in a country with a paucity 624 of standard virtual care. Further, only a single reviewer screened the included studies, therefore 625 unconscious selection bias may be at play, however studies show that this approach still 626 represents an appropriate methodological shortcut. ${ }^{82}$ Strengths of this review include the use of 627 an experienced librarian for the development of the search strategy and adherence to the 628 PRISMA guidelines. 
medRxiv preprint doi: https://doi.org/10.1101/2020.12.17.20248333; this version posted December 19, 2020. The copyright holder for this preprint (which was not certified by peer review) is the author/funder, who has granted medRxiv a license to display the preprint in perpetuity.

\section{$630 \quad$ Future Directions}

631 Many important areas relating to virtual care were not well addressed and require further study.

632 These include: 1) the role of the public and private sectors in evaluating, disseminating, and

633 overseeing the use of virtual care technology, 2) appropriate remuneration rates for using virtual

634 care technology, 3) incentivizing a priori criteria for using/adopting virtual care technology, and

635 4) preparing future healthcare providers to incorporate virtual care technology in cardiovascular

636 practices, such as providing training in undergraduate medical education programs and providing

637 continuing medical education credits.

\section{Conclusion}

640 In sum, it is clear that efforts are being made to ensure equitable care of patients diagnosed with

641 all subtypes of CVD, although future studies targeted in the realm of hypertension management

642 among rural Canadian populations are greatly needed. The systems for acute pathologies seem to

643 be the most well-established, while those focused on chronic cardiac conditions remain in the

644 pilot phase. The evidence presented here also indicates potential for long-term healthcare savings

645 with virtual care solutions. Given the themes identified in this review that virtual care

646 technologies are efficacious, well-accepted, and economical, we feel that these systems should

647 be adopted and better integrated into clinical cardiology practices in order to care for patients

648 diagnosed with CVD living in rural areas of Canada. Funding and partner agencies should

649 prioritize high-risk high-reward regions with considerable rural populations to maximize early

650 returns on investments in virtual care. 
medRxiv preprint doi: https://doi.org/10.1101/2020.12.17.20248333; this version posted December 19, 2020. The copyright holder for this preprint (which was not certified by peer review) is the author/funder, who has granted medRxiv a license to display the preprint in perpetuity. All rights reserved. No reuse allowed without permission.

\section{Acknowledgments}

652 The authors would like to acknowledge the help of Jackie Phinney (Librarian, W.K. Kellogg

653 Health Sciences Library, Dalhousie University) who assisted in the development of the literature

654 search strategy.

\section{Funding Source Declaration}

657 This work was generously supported by AGE-WELL NCE Inc., a member of the Networks of 658 Centres of Excellence program, the New Brunswick Health Research Foundation and the New 659 Brunswick Innovation Foundation. Neither of these organizations played a role in the design, 660 data collection, analysis, or interpretation of this literature review, or in preparation of this 661 manuscript.

\section{Declarations of Interest}

664 KRB has a direct financial interest in medical technology innovation companies as a director or 665 shareholder of: NBBM Inc. and Routinify Inc.; has received partnership grant/contract funding 666 or financial in-kind support from or serves as a medical science advisor to: Ausculsciences Inc.; 667 BaioTeq Inc.; Cloud-Dx Inc.; eVisitNB (Maple Inc.); Medtronic Canada Inc.; Serviere Canada

668 Inc.; IBM Canada; and the Government of New Brunswick. HC has a direct financial interest in 669 medical technology innovation companies as a director or shareholder of eVisitNB (Maple Inc.) $670 \mathrm{JFL}$ and SL have received medical technology innovation partnership grant/contract funding or 671 financial in-kind support from Medtronic Inc.; Serviere Canada Inc. RB, SM, and CWW have no 672 conflicts of interest to disclose relevant to the present work. None of these enterprises played a 673 role in the design, data collection, analysis, or interpretation of this literature review, or in 674 preparation of this manuscript. 
medRxiv preprint doi: https://doi.org/10.1101/2020.12.17.20248333; this version posted December 19, 2020. The copyright holder for this preprint (which was not certified by peer review) is the author/funder, who has granted medRxiv a license to display the preprint in perpetuity.

All rights reserved. No reuse allowed without permission.

\section{Appendix}

677

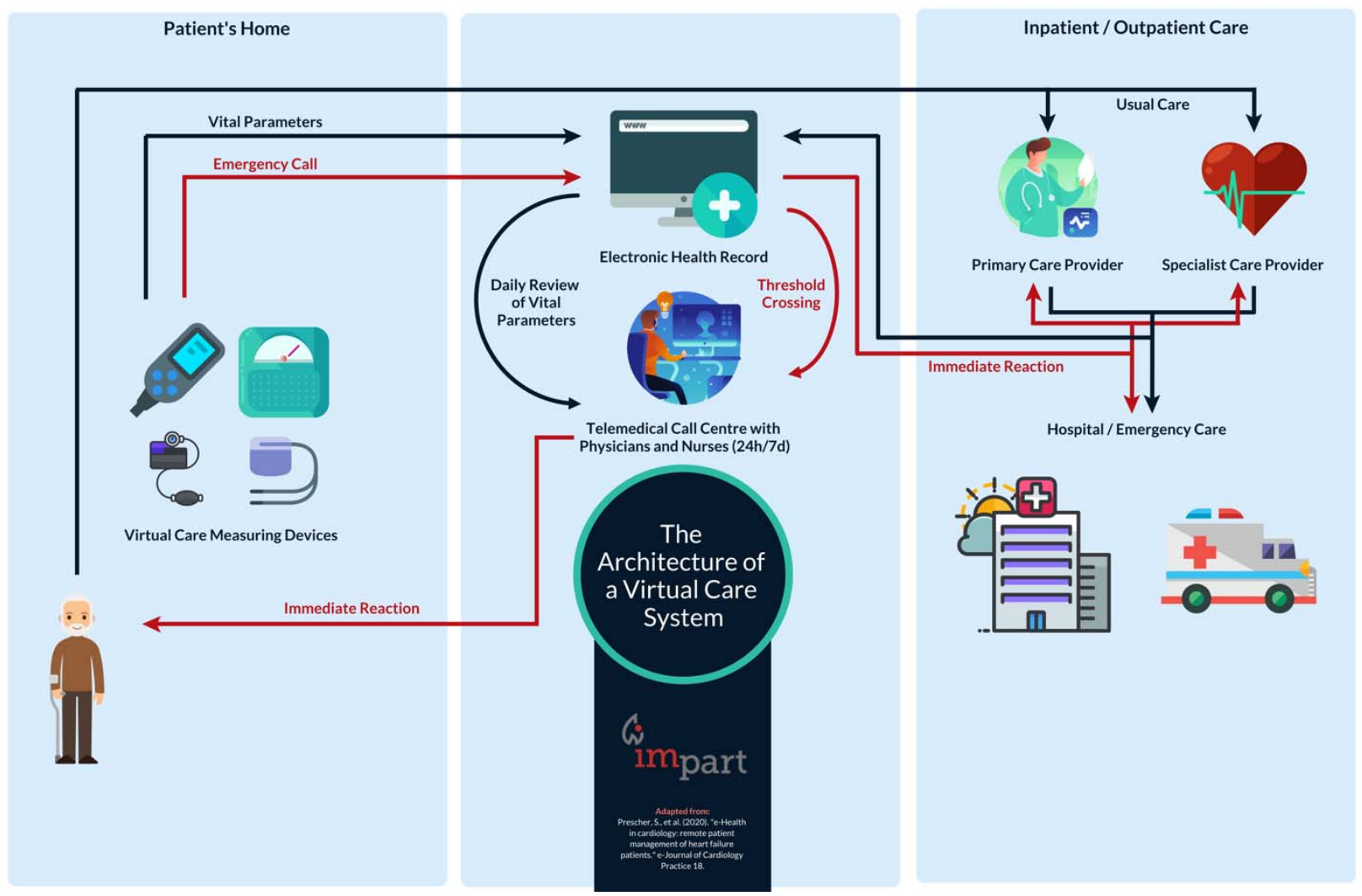

Figure 1. The architecture of a virtual care system. 
medRxiv preprint doi: https://doi.org/10.1101/2020.12.17.20248333; this version posted December 19, 2020. The copyright holder for this preprint (which was not certified by peer review) is the author/funder, who has granted medRxiv a license to display the preprint in perpetuity.

All rights reserved. No reuse allowed without permission.

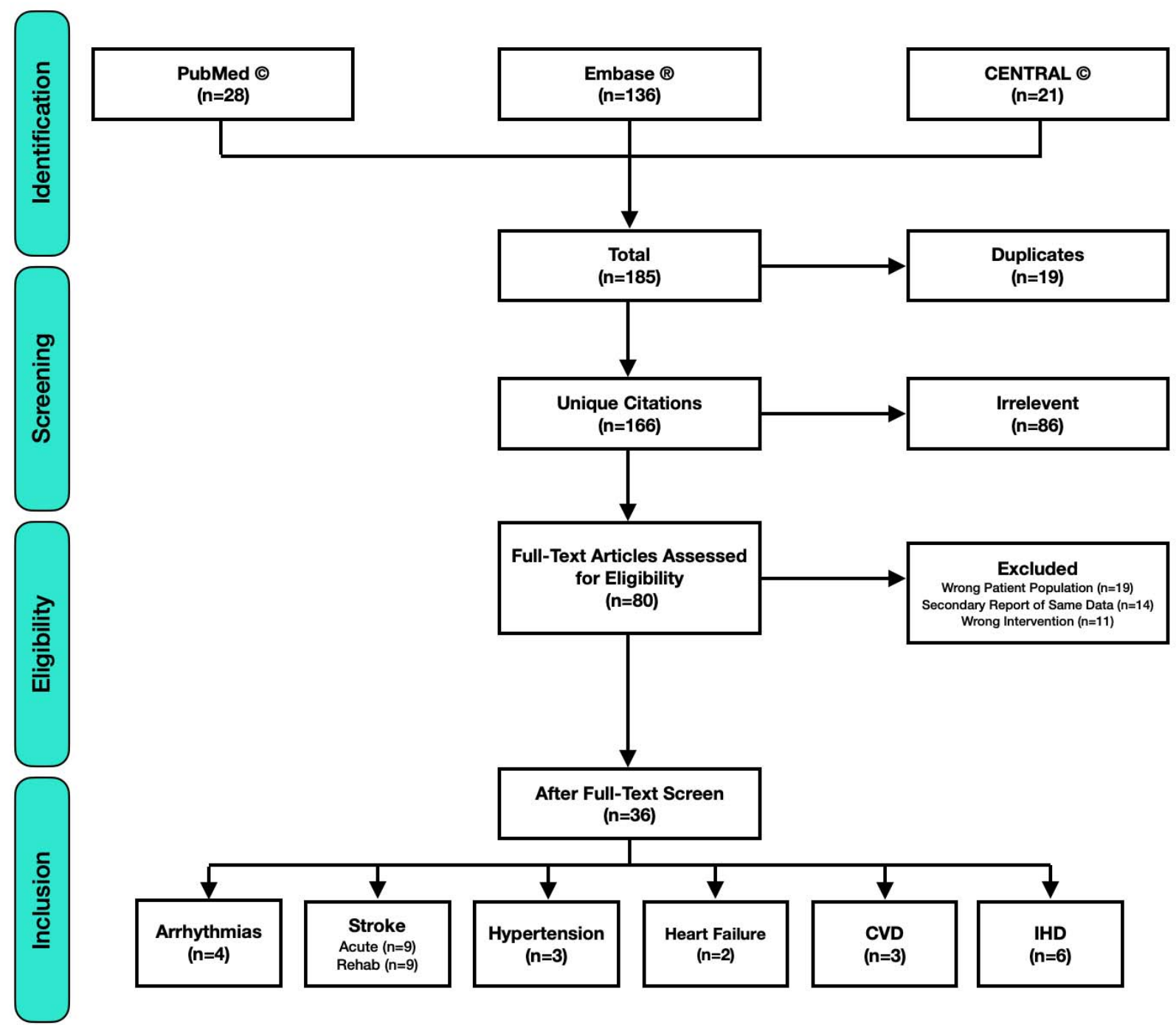

Figure 2. Flow chart of literature search and study extraction process, where $\mathrm{n}$ represents the number of studies in each group. 
medRxiv preprint doi: https://doi.org/10.1101/2020.12.17.20248333; this version posted December 19, 2020. The copyright holder for this preprint (which was not certified by peer review) is the author/funder, who has granted medRxiv a license to display the preprint in perpetuity.

All rights reserved. No reuse allowed without permission.

Figure 3. Summary of virtual care recommendations.

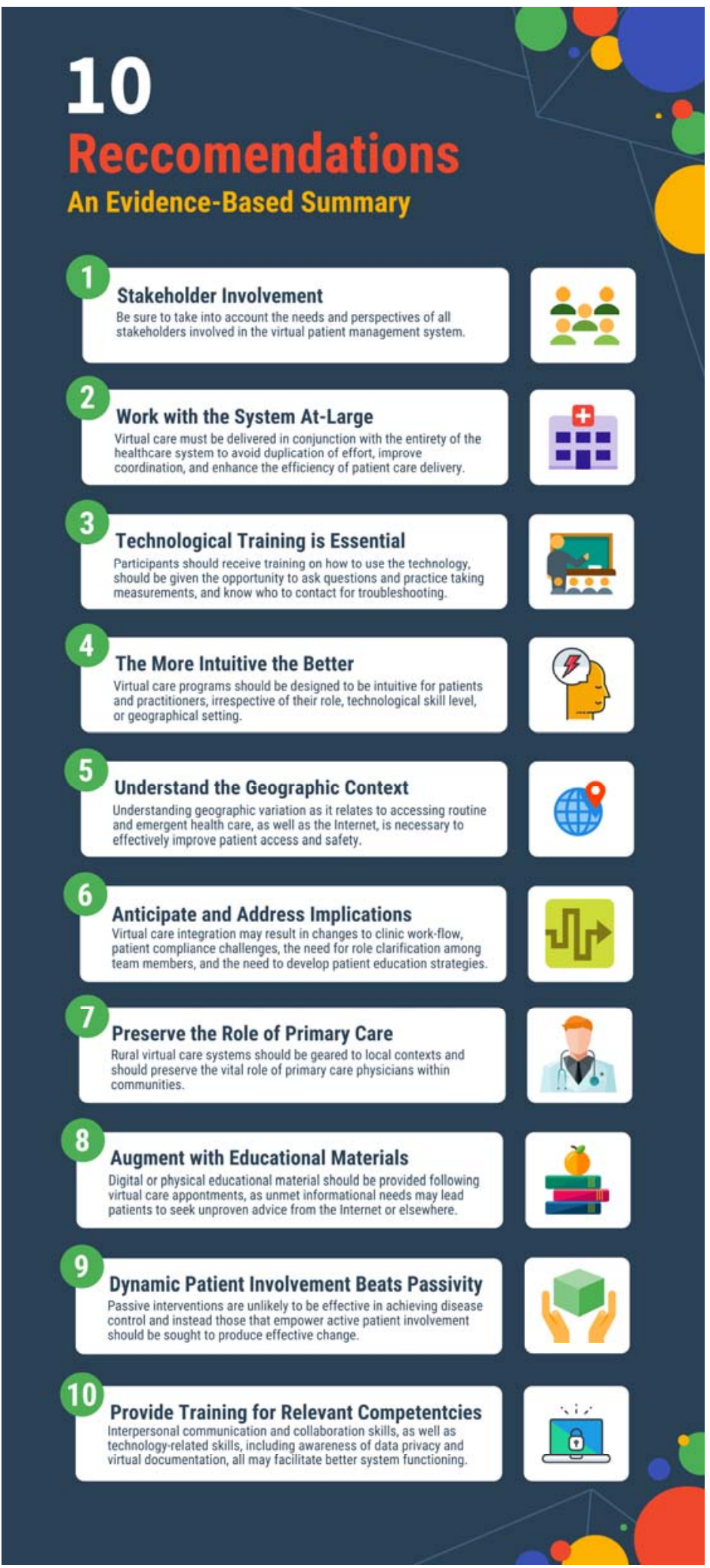


medRxiv preprint doi: https://doi.org/10.1101/2020.12.17.20248333; this version posted December 19, 2020. The copyright holder for this preprint (which was not certified by peer review) is the author/funder, who has granted medRxiv a license to display the preprint in perpetuity.

All rights reserved. No reuse allowed without permission.

681

Figure 4. Summary of practical objectives for future virtual care programs.
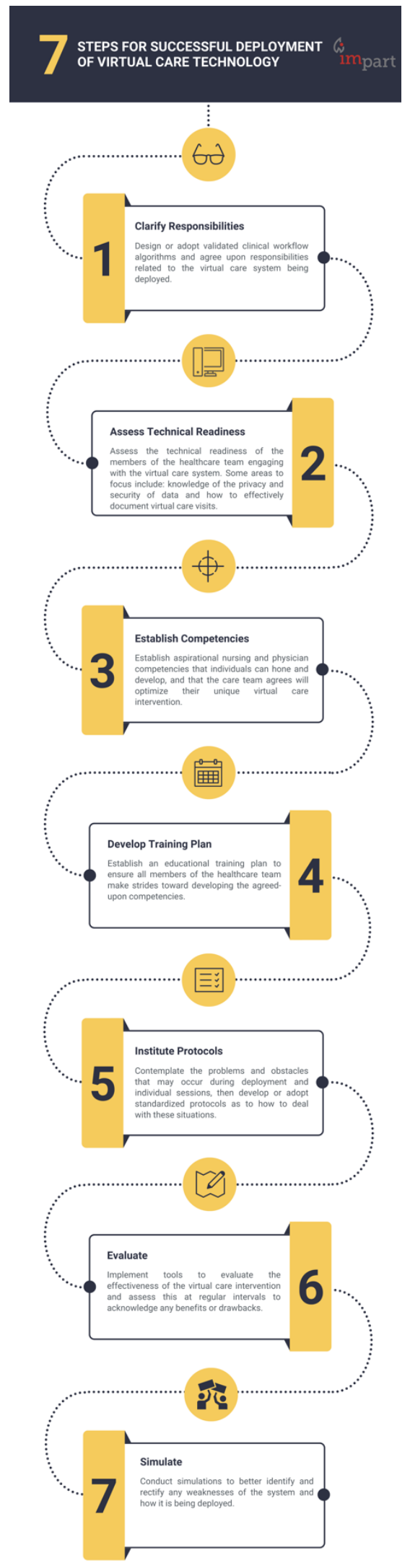
medRxiv preprint doi: https://doi.org/10.1101/2020.12.17.20248333; this version posted December 19, 2020. The copyright holder for this preprint (which was not certified by peer review) is the author/funder, who has granted medRxiv a license to display the preprint in perpetuity.

\section{$\underline{\text { References }}$}

683 1. Canadian Institute for Health Information, Disparities in Primary Health Care Experience 684 Among Canadians with Ambulatory Care Sensitive Conditions. 2012.

685 2. Garcia, M.C., et al., Reducing Potentially Excess Deaths from the Five Leading Causes of 686 Death in the Rural United States. MMWR Surveill Summ, 2017. 66(2): p. 1-7.

687 3. Subedi, R., T.L. Greenberg, and S. Roshanafshar, Does geography matter in mortality? An 688 analysis of potentially avoidable mortality by remoteness index in Canada. Statistics 689 Canada Health Reports, 2019.

690 4. Ahmed, S. and R.K. Shahid, Disparity in cancer care: a Canadian perspective. Curr Oncol, 2012. 19(6): p. e376-82.

692 5. Luu, J., et al., Access to Routine Medical Care and Cardiovascular Disease Outcomes in a Rual Canadian Population. Canadian Journal of Cardiology, 2017. 33(10).

694 6. Benchimol, E.I., et al., Rural and urban disparities in the care of Canadian patients with inflammatory bowel disease: a population-based study. Clin Epidemiol, 2018. 10: p. 16131626.

697 7. Canadian Medical Association, Ensuring equitable access to care: Strategies for Governments, Health System Planners, and the Medical Profession. 2013.

699 8. Canadian Institute for Health Information, Health Care in Canada: A Focus on Wait $700 \quad$ Times. 2012.

701 9. Owens, B., Telemedicine on the rise but lagging in Canada. CMAJ, 2018. 190(38): p. E1149-E1150.

703 10. Prescher, S., J. Koehler, and F. Koehler, e-Health in cardiology: remote patient 704 management of heart failure patients. e-Journal of Cardiology Practice, 2020. 18. 
medRxiv preprint doi: https://doi.org/10.1101/2020.12.17.20248333; this version posted December 19, 2020. The copyright holder for this preprint (which was not certified by peer review) is the author/funder, who has granted medRxiv a license to display the preprint in perpetuity. All rights reserved. No reuse allowed without permission.

705 11. Canadian Medical Association (2020). Virtual care: Recommendations for scaling up 706 virtual medical services. From: https://www.cma.ca/sites/default/files/pdf/virtual$707 \quad$ care/ReportoftheVirtualCareTaskForce.pdf

708 12. The World Health Organization, WHO eHealth Resolution 58.28. 2005.

709 13. Castro, D., B. Miller, and A. Nager, Unlocking the Potential of Physician-to-Patient $710 \quad$ Telehealth Services. Information Technology and Innovation Foundation, 2014.

711 14. Board on Health Care Services; Institute of Medicine, The Evolution of Telehealth: Where Have We Been and Where Are We Going? The Role of Telehealth in an Evolving Health Care Environment: Workshop Summary., N.A.P. (US), Editor. 2012: Washington (DC).

714 15. Cannon, C., Telehealth, Mobile Applications, and Wearable Devices are Expanding $715 \quad$ Cancer Care Beyond Walls. Semin Oncol Nurs, 2018. 34(2): p. 118-125.

716 16. Lim, S.S., et al., A comparative risk assessment of burden of disease and injury attributable 717 to 67 risk factors and risk factor clusters in 21 regions, 1990-2010: a systematic analysis 718 for the Global Burden of Disease Study 2010. Lancet, 2012. 380(9859): p. 2224-60.

719 17. James, P.A., et al., 2014 evidence-based guideline for the management of high blood $720 \quad$ pressure in adults: report from the panel members appointed to the Eighth Joint National 721 Committee (JNC 8). JAMA, 2014. 311(5): p. 507-20.

722 18. Padwal, R.S., et al., Cost-effectiveness of home blood pressure telemonitoring and case 723 management in the secondary prevention of cerebrovascular disease in Canada. $\mathrm{J}$ Clin 724 Hypertens (Greenwich), 2019. 21(2): p. 159-168.

725 19. Lang, J. J., et al. (2018). Global Burden of Disease Study trends for Canada from 1990 to 726 2016. CMAJ 190(44): E1296-E1304. 
medRxiv preprint doi: https://doi.org/10.1101/2020.12.17.20248333; this version posted December 19, 2020. The copyright holder for this preprint (which was not certified by peer review) is the author/funder, who has granted medRxiv a license to display the preprint in perpetuity. All rights reserved. No reuse allowed without permission.

727 20. Benjamin, E.J., et al., Heart Disease and Stroke Statistics-2018 Update: A Report from the 728 American Heart Association. Circulation, 2018. 137(12): p. e67-e492.

729 21. Moher, D., et al., Preferred reporting items for systematic reviews and meta-analyses: the

$730 \quad$ PRISMA statement. PLoS Med, 2009. 6(7): p. e1000097.

731 22. Jarvis-Selinger, S., et al., Internet-based support for cardiovascular disease management.

732 International Journal of Telemedicine and Applications, 2011

733 23. Cameron, J.E., et al., "In this together": Social identification predicts health outcomes (via 734 self-efficacy) in a chronic disease self-management program. Social Science and Medicine, 735 2018. 208: p. 172-179.

736 24. Stuckey, M.I., et al., A lifestyle intervention supported by mobile health technologies to 737 improve the cardiometabolic risk profile of individuals at risk for cardiovascular disease 738 and type 2 diabetes: study rationale and protocol. BMC Public Health, 2013. 13: p. 1051.

739 25. Andrikopoulou, E., K. Abbate, and D.J. Whellan, Conceptual model for heart failure 740 disease management. Canadian Journal of Cardiology, 2014. 30(3): p. 304-311.

741 26. Grant, R., et al., Cardiovascular nurses: The key factor in the success of the first Canadian 742 heart failure remote monitoring clinic. Canadian Journal of Cardiology, 2012. 28(5): p. $743 \quad$ S432.

744 27. Wassef, A.W., et al., A first in Canada: The St. Boniface Hospital heart failure remote 745 monitoring clinic experience. Canadian Journal of Cardiology, 2012. 28(5): p. S342-S343.

746 28. Toback, M., The effectiveness of telehealth nursing in heart failure self-management. 747 Canadian Journal of Cardiology, 2017. 33(10): p. S213-S214.

748 29. TEC4Home Healthcare Innovation Community. Supporting Heart Failure Patient 749 Transitions from Acute to Community Care with Home Telemonitoring Technology: A 
medRxiv preprint doi: https://doi.org/10.1101/2020.12.17.20248333; this version posted December 19, 2020. The copyright holder for this preprint (which was not certified by peer review) is the author/funder, who has granted medRxiv a license to display the preprint in perpetuity. All rights reserved. No reuse allowed without permission.

Protocol for a Provincial Randomized Controlled Trial (TEC4Home). JMIR Res Protoc, 2016. 5(4): p. e198.

752 30. Novak Lauscher, H., et al., TEC4Home heart failure: Using home telemonitoring to 753 decrease ED readmissions and clinical flow. Canadian Journal of Emergency Medicine, 2018. 20: p. S56-S57.

755 31. Hage, E., et al., Implementation factors and their effect on e-Health service adoption in rural communities: a systematic literature review. BMC Health Serv Res, 2013. 13: p. 19.

757 32. Jaana, M. and H. Sherrard, Rural-Urban Comparison of Telehome Monitoring for Patients with Chronic Heart Failure. Telemedicine Journal and e-Health from the American Telemedicine Association, 2019. 25(2): p. 101-108.

33. Fraser, J.D., et al., Guidelines for pacemaker follow-up in Canada: a consensus statement of the Canadian Working Group on Cardiac Pacing. Can J Cardiol, 2000. 16(3): p. 355-63, 367-76.

763 34. Gillis, A.M., et al., Guidelines for implantable cardioverter defibrillator follow-up in Canada: a consensus statement of the Canadian Working Group on Cardiac Pacing. Can J Cardiol, 2003. 19(1): p. 21-37.

35. Yee, R., et al., Canadian Cardiovascular Society/Canadian Heart Rhythm Society Joint Position Statement on the Use of Remote Monitoring for Cardiovascular Implantable Electronic Device Follow-up. Canadian Journal of Cardiology, 2013. 29(6): p. 644-651. Canada): p. 133D. 
medRxiv preprint doi: https://doi.org/10.1101/2020.12.17.20248333; this version posted December 19, 2020. The copyright holder for this preprint (which was not certified by peer review) is the author/funder, who has granted medRxiv a license to display the preprint in perpetuity. All rights reserved. No reuse allowed without permission.

772 37. Flavelle, S., et al., Remote monitoring for ICD follow-up: Connecting technology, clinic 773 processes, patient care and best practice. Canadian Journal of Cardiology, 2011. 27(5): p. $774 \quad$ S354.

775 38. Forman, J., et al., Evaluating the integration of remote monitoring for cardiovascular 776 implantable electronic device follow-up. Canadian Journal of Cardiology, 2014. 30(10): p. S357-S358.

39. Sparkes, J., R. Valaitis, and A. McKibbon, A usability study of patients setting up a cardiac event loop recorder and BlackBerry gateway for remote monitoring at home. Telemedicine Journal and e-Health from the American Telemedicine Association, 2012. 18(6): p. 484490.

40. Rush, K.L., et al., Planning Telehealth for Older Adults with Atrial Fibrillation in Rural Communities: Understanding Stakeholder Perspectives. Clinical Nursing Research, 2019. 28(2): p. 130-149.

41. Rush, K.L., et al., Atrial fibrillation care in rural communities: a mixed methods study of physician and patient perspectives. BMC Family Practice, 2019. 20(1): p. 144.

42. Tanguay, A., et al., Detection of STEMI Using Prehospital Serial 12-Lead Electrocardiograms. Prehosp Emerg Care, 2018. 22(4): p. 419-426.

43. O'Gara, P.T., et al., 2013 ACCF/AHA guideline for the management of ST-elevation myocardial infarction: a report of the American College of Cardiology Foundation/American Heart Association Task Force on Practice Guidelines. Circulation, 2013. 127(4): p. e362-425. 
medRxiv preprint doi: https://doi.org/10.1101/2020.12.17.20248333; this version posted December 19, 2020. The copyright holder for this preprint (which was not certified by peer review) is the author/funder, who has granted medRxiv a license to display the preprint in perpetuity. All rights reserved. No reuse allowed without permission.

44. Tanguay, A., et al., Rural Patient Access to Primary Percutaneous Coronary Intervention Centers is Improved by a Novel Integrated Telemedicine Prehospital System. Journal of Emergency Medicine, 2015. 49(5): p. 657-664.

45. Lear, S.A., The Delivery of Cardiac Rehabilitation Using Communications Technologies: The "Virtual" Cardiac Rehabilitation Program. The Canadian Journal of Cardiology, 2018. 34(10 Suppl 2): p. S278-S283.

46. Lear, S.A., et al., Randomized trial of a 'virtual' cardiac rehabilitation program delivered at a distance via the internet. Circulation, 2013. 128(22).

47. Mendell, J., et al., What Do Patients Talk About? A Qualitative Analysis of Online Chat Sessions with Health Care Specialists During a "Virtual" Cardiac Rehabilitation Program. Telemedicine Journal and e-Health from the American Telemedicine Association, 2019.

48. Pistawka, A., J. Gabelhouse, and D. Butts, Telehealth delivery of cardiac education to

49. Campbell, N., et al., A framework for discussion on how to improve prevention, management, and control of hypertension in Canada. Can J Cardiol, 2012. 28(3): p. 262-9.

50. Tobe, S.W., et al., Effect of nurse-directed hypertension treatment among First Nations people with existing hypertension and diabetes mellitus: The Diabetes Risk Evaluation and Microalbuminuria (DREAM 3) randomized controlled trial. CMAJ, 2006. 174(9): p. 1267-

813 51. Yeates, K., et al., The Effectiveness of Text Messaging for Detection and Management of Hypertension in Indigenous People in Canada: Protocol for a Randomized Controlled 815 Trial. JMIR research protocols, 2017. 6(12): p. e244. 
medRxiv preprint doi: https://doi.org/10.1101/2020.12.17.20248333; this version posted December 19, 2020. The copyright holder for this preprint (which was not certified by peer review) is the author/funder, who has granted medRxiv a license to display the preprint in perpetuity. All rights reserved. No reuse allowed without permission.

52. Tobe, S.W., et al., Diagnosing hypertension in Indigenous Canadians (DREAM-GLOBAL): A randomized controlled trial to compare the effectiveness of short message service messaging for management of hypertension: Main results. Journal of Clinical Hypertension, 2019. 21(1): p. 29-36.

53. Padwal, R.S., Designing interventions for blood pressure control in challenging settings: Active not passive intervention is needed. Journal of Clinical Hypertension (Greenwich, Conn.), 2019. 21(1): p. 37-38.

54. Peltier, C. (2018). An Application of Two-Eyed Seeing: Indigenous Research Methods with Participatory Action Research. International Journal of Qualitative Methods 17.

55. Saver, J.L., Time is brain--quantified. Stroke, 2006. 37(1): p. 263-6.

56. Blacquiere, D., et al., Canadian Stroke Best Practice Recommendations: Telestroke Best Practice Guidelines Update 2017. International Journal of Stroke, 2017. 12(8): p. 886-895.

57. Hakim, A.M., The future of stroke thrombolysis. 2012. p. 8-13.

58. Zimmer, L. and L. Kelloway, A clinical toolkit to support acute stroke management using Telestroke in Ontario. Canadian Journal of Neurological Sciences, 2010. 37(3): p. S96.

59. Taralson, C., et al., Telestroke in a remote site: One Northern Alberta hospital's experience establishing acute stroke treatment by telehealth. Stroke, 2014. 45(12): p. e285.

60. Taralson, C., et al., The expansion of telestroke across the continuum of care. Stroke, 2014. 45(12): p. e265-e266.

61. Glasser, E., et al., Nursing competencies for telestroke. International Journal of Stroke, 2015. 10((Lindsay P.) Heart and Stroke Foundation, Toronto, Canada): p. 48.

62. Khan, K.A., et al., Telestroke in northern Alberta, Canada: A two-year experience with small remote hospitals. Stroke, 2010. 41(4): p. e262-e263. 
medRxiv preprint doi: https://doi.org/10.1101/2020.12.17.20248333; this version posted December 19, 2020. The copyright holder for this preprint (which was not certified by peer review) is the author/funder, who has granted medRxiv a license to display the preprint in perpetuity. All rights reserved. No reuse allowed without permission.

839 63. Silver, F.L., Telestroke: The management of acute ischemic stroke from a distance.

$840 \quad$ Canadian Journal of Neurological Sciences, 2010. 37(6): p. 717-718.

841 64. Jeerakathil, T., et al., Thrombolysis using telehealth has comparable results to non842 telehealth thrombolysis across northern Alberta: The Alberta provincial stroke strategy

843 (APSS). Stroke, 2012. 43(2).

844 65. Khan, F.B., et al., Acute stroke care: Telestroke vs. on-site stroke specialist care. Results 845 from the Ontario telestroke experience. Stroke, 2011. 42(3): p. e340.

846 66. Shuaib, A., et al., Introduction of portable computed tomography scanners, in the treatment 847 of acute stroke patients via telemedicine in remote communities. International Journal of $848 \quad$ Stroke, 2010. 5(2): p. 62-66.

849 67. Shuaib, A. and T. Jeerakathil, The mobile stroke unit and management of acute stroke in rural settings. CMAJ, 2018. 190(28): p. E855-E858.

851 68. Mitchell, J.R., et al., A smartphone client-server teleradiology system for primary diagnosis of acute stroke. Journal of Medical Internet Research, 2011. 13(2): p. e31.

853 69. Bodnar, P., Developing an aboriginal stroke strategy in Northwestern Ontario. Stroke, $854 \quad$ 2011. 42(11): p. e622-e623.

855 70. French, E.H., K.J. Reinikka, and M.P. Huijbregts, Tele-rehab: The feasibility of using 856 telemedicine to deliver interprofessional stroke rehabilitation consultations in northern, 857 rural and remote communities. Stroke, 2010. 41(7): p. e506.

858 71. Linkewich, E., K. Harrington, and A. Oikonen, "Virtual" home safety assessment after 859 stroke in remote aboriginal communities. Canadian Journal of Neurological Sciences, 860 2010. 37(3): p. S100. 
medRxiv preprint doi: https://doi.org/10.1101/2020.12.17.20248333; this version posted December 19, 2020. The copyright holder for this preprint (which was not certified by peer review) is the author/funder, who has granted medRxiv a license to display the preprint in perpetuity. All rights reserved. No reuse allowed without permission.

861 72. Taylor, D.M., S.D. Stone, and M.P. Huijbregts, Remote participants' experiences with a 862 group-based stroke self-management program using videoconference technology. Rural 863 and Remote Health, 2012. 12((Stone S.D.; Huijbregts M.P.)): p. 1947.

864 73. Whelan, K., A. Gardner, and M. Kelly, The Saskatchewan cerebrovascular center: Telehealth pilot project. Stroke, 2014. 45(12): p. e278-e279.

866 74. Sakakibara, B.M., et al., A telehealth intervention to promote healthy lifestyles after stroke: 867 the stroke coach protocol. Stroke, 2014. 45(12): p. e285.

868 75. Appireddy, R., et al., Home Virtual Visits for Outpatient Follow-Up Stroke Care: Cross869 Sectional Study. Journal of Medical Internet Research, 2019. 21(10): p. e13734.

870 76. Statistics Canada (2018). Canada goes urban. from 871 https://www150.statcan.gc.ca/n1/pub/11-630-x/11-630-x2015004-eng.htm.

872 77. Arnold, R.H., et al., Rural and Remote Cardiology During the COVID-19 Pandemic: 873 Cardiac Society of Australia and New Zealand (CSANZ) Consensus Statement. Heart Lung $874 \quad$ Circ, 2020.

875 78. Kim, K.K., et al., A Novel Stakeholder Engagement Approach for Patient-centered $876 \quad$ Outcomes Research. Med Care, 2018. 56 Suppl 10: p. S41-S47.

877 79. Ross, H., et al., Treating the right patient at the right time: access to heart failure care. Can $878 \quad$ J Cardiol, 2006. 22(9): p. 749-54.

879 80. Statistics Canada (2011). Canada's rural population since 1851. from 880 https://www12.statcan.gc.ca/census-recensement/2011/as-sa/98-310-x/98-310-

$881 \quad \underline{\text { 22011003 2-eng.cfm }}$ 
medRxiv preprint doi: https://doi.org/10.1101/2020.12.17.20248333; this version posted December 19, 2020. The copyright holder for this preprint (which was not certified by peer review) is the author/funder, who has granted medRxiv a license to display the preprint in perpetuity. All rights reserved. No reuse allowed without permission.

882 81. The Commonwealth Fund (2019). Average Annual Number of Physician Visits per Capita,

883 2017. from https://www.commonwealthfund.org/international-health-policy-center/system-

$884 \quad$ stats/annual-physician-visits

885 82. Waffenschmidt, S., et al., Single screening versus conventional double screening for study

886 selection in systematic reviews: a methodological systematic review. BMC Med Res

$887 \quad$ Methodol, 2019. 19(1): p. 132. 